Revue de l'Institut des langues et cultures

d'Europe, Amérique, Afrique, Asie et Australie

$41 \mid 2020$

Escrituras nómadas en el mundo hispánico contemporáneo

\title{
Figuraciones de la subjetividad contemporánea y poética de la errancia en Después del invierno de Guadalupe Nettel
}

Figurations de la subjectivité contemporaine et poétique de l'errance dans Después del invierno de Guadalupe Nettel

Figurations of Contemporary Subjectivity and Nomadic Poetics in Guadalupe Nettel's Después del invierno

Roberta Tennenini

\section{OpenEdition}

Journals

Edición electrónica

URL: http://journals.openedition.org/ilcea/11093

DOI: 10.4000/ilcea.11093

ISSN: 2101-0609

Editor

UGA Éditions/Université Grenoble Alpes

Edición impresa

ISBN: 978-2-37747-224-6

ISSN: 1639-6073

Referencia electrónica

Roberta Tennenini, «Figuraciones de la subjetividad contemporánea y poética de la errancia en

Después del invierno de Guadalupe Nettel», ILCEA [En línea], 41 | 2020, Publicado el 03 noviembre 2020, consultado el 02 febrero 2021. URL: http://journals.openedition.org/ilcea/11093 ; DOI: https://doi.org/ 10.4000/ilcea.11093

Este documento fue generado automáticamente el 2 febrero 2021.

(C) ILCEA 


\title{
Figuraciones de la subjetividad contemporánea y poética de la errancia en Después del invierno de Guadalupe Nettel
}

\author{
Figurations de la subjectivité contemporaine et poétique de l'errance dans \\ Después del invierno de Guadalupe Nettel \\ Figurations of Contemporary Subjectivity and Nomadic Poetics in Guadalupe \\ Nettel's Después del invierno
}

\section{Roberta Tennenini}
L'aleph, ce lieu borgésien où le monde entier est simultanément visible, est-il autre chose qu'un alphabet?
Georges Perec, Espèces d'espaces

1 En su libro Radicante, Nicolas Bourriaud sostiene que la realidad histórica y social actual -la de la globalización de los estilos de vida, de los flujos migratorios y del nomadismo planetario- constituye una superación del multiculturalismo posmoderno y se caracteriza por «la cooperación entre una multitud de semas culturales» y por «la traducción permanente de las singularidades» (2009: 42). Dicho de otro modo, la modernidad específica del siglo xxI está determinada por una reinvención constante de nuestro imaginario colectivo y por un cuestionamiento de las nociones de origen y diversidad cultural en favor de «una forma de pensamiento susceptible de operar interconexiones entre culturas dispares» (2009: 43). Este cambio epocal, que el historiador y crítico de arte francés define como «altermodernidad», se caracteriza por la emergencia de una ética de la precariedad y de una estética de la errancia, esto es, por un marcado dinamismo de los discursos y de las formas.

2 Como era de esperarse, la incidencia de este fenómeno en la creación literaria contemporánea es notable. En ámbito hispanoamericano, los trabajos de Francisca 
Noguerol (2008) y Fernando Aínsa $(2006,2012)$, entre otros, han contribuido a la identificación de nuevos paradigmas expresivos y al bosquejo de los principales rasgos que definen la literatura más reciente. Entre ellos, se destaca la extraterritorialidad, que podría definirse como la tendencia de los autores contemporáneos a rebasar la dimensión local y las fronteras nacionales para relatar una realidad transnacional e incluir en sus ficciones los procesos de desterritorialización y reterritorialización que determinan nuestro presente y afectan nuestra manera de estar en el mundo.

3 Es en este contexto que cabe situar la obra de Guadalupe Nettel (1973), una de las voces más destacadas en el actual panorama de las letras hispanoamericanas. En efecto, por razones biográficas y culturales ${ }^{1}$, la autora mexicana encarna esa nueva cartografía de la pertenencia teorizada por Fernando Aínsa en su célebre ensayo (2012) y por Rosi Braidotti en sus precursores trabajos sobre la noción de nomadismo $(1994,2000)$. Autora de cuentos, novelas y ensayos ${ }^{2}$, Guadalupe Nettel ha convertido esa «ciudadanía flexible» (Braidotti, 2002: 25) en una mirada literaria descentrada, que presta atención a lo extraño y lo nimio para escudriñar los recovecos del alma humana e interrogar el presente desde los márgenes de la realidad.

4 Con Después del invierno (2014), obra que nos ocupa, la escritora mexicana ganó el Premio Herralde de Literatura, un galardón del que había sido finalista ya en 2005 con El huésped y que fue precedido por otros importantes reconocimientos literarios, tales como el Premio Nacional de Cuentos Gilberto Owen (2007), el Premio Anna Seghers (2009) o el Premio de Narrativa Breve Ribera del Duero (2013).

5 Si en todas sus creaciones Guadalupe Nettel celebra la excentricidad en que se cifra la existencia humana, en Después del invierno, su última novela, cuenta la historia de unos personajes que viven en otros países y en otras lenguas y cuyas vidas se ven marcadas por una serie de tránsitos reales y simbólicos: la migración, el viaje, la enfermedad física y psíquica, el amor y sus desencuentros, la pérdida. Así, a partir de unos elementos autobiográficos que deconstruye y reinventa, la autora traza un retrato ejemplar de la identidad nomádica de nuestros tiempos mediante las voces de los dos protagonistas de la novela: Claudio, un cubano exiliado en Nueva York, y Cecilia, una mexicana becaria en París.

6 A la luz de estas reflexiones preliminares, nos proponemos analizar la novela Después del invierno de Guadalupe Nettel para comprender cómo la literatura hispanoamericana está asumiendo el reto de representar la altermodernidad y sus cambios incesantes. En otros términos, ¿en qué medida «el predominio en todos los campos del pensamiento y de la creación de lo transitorio» (Bourriaud, 2009: 97) afecta a los escritores contemporáneos? Y ¿de qué maneras los procesos de desterritorialización y reterritorialización que caracterizan nuestra época se reflejan en los temas, las tramas y las formas de la novela actual? La escritura de Guadalupe Nettel representa, a nuestro parecer, un excelente material para reflexionar en torno a estos interrogantes. Así, para brindar unas respuestas, provisorias y parciales, a tales cuestionamientos, en las páginas que siguen, analizamos los que nos parecen ser los tres aspectos más significativos de la novela, a saber: la representación de una subjetividad descentrada y radicante, la puesta en escena de la fragilidad de las relaciones humanas y la elaboración de una poética de la errancia. 


\section{Figuraciones de una subjetividad descentrada y radicante}

7 Según afirma Rosi Braidotti, la noción de «sujetos nómades» es «una figuración teorética conveniente para [representar] la subjetividad contemporánea» (2000: 26), puesto que refleja la condición existencial de una multitud de individuos transculturales que se desplazan y se adaptan sin cesar a una variedad de circunstancias cambiantes. De ahí la necesidad de considerar «la conciencia nómade [como] un imperativo epistemológico y político para el pensamiento crítico del fin del milenio» (2000: 26). En este sentido, para la filósofa italiana, el nomadismo es, al mismo tiempo, una evidencia socio-histórica y un estilo de pensamiento, cuyo objetivo es resistir críticamente a los «modos socialmente codificados de pensamiento y conducta» (2000: 31) y a las «identidades hegemónicas de todo tipo» (2000: 39). Si la atención de Braidotti se centra principalmente en la construcción de una subjetividad alternativa feminista, su reflexión se extiende a la elaboración de una «estética nómade» y al universo de la creación literaria: el nómade es un políglota -afirma Braidotti- y escribir es «llegar a ser un políglota en la propia lengua materna» (2000: 47). Existe, entonces, una relación muy estrecha entre la vertiginosa deconstrucción de la identidad que caracteriza el nomadismo y el gesto de captar el devenir incesante de la realidad contemporánea por medio de la escritura literaria.

Al respecto, parece oportuno mencionar las palabras de Fernando Aínsa, quien en su imprescindible ensayo, sintetiza así el devenir de la literatura latinoamericana:

el canon actual de la literatura latinoamericana está disperso. Ha perdido sus indicadores nacionales tradicionales y refleja [...] el desmoronamiento del metaconcepto [de identidad] que la unificaba alrededor de nociones como territorio, pueblo, nación, país, comunidad, raíces. (2012: p. irr.)

El contexto socio-histórico, la movilidad de los propios escritores y la emergencia de antihéroes y seres marginales en literatura han contribuido - según señala Aínsa- a la descolocación del autor y del personaje: un desajuste que está al origen de la renovación de la novela «tanto en lo formal como en lo sustancial» (2012: p. irr.). En efecto, en Después del invierno, la autora deja el manejo de la narración a sus dos protagonistas: dos seres que, en búsqueda de un espacio propio lejos de su patria, proyectan una mirada crítica - multipolar- sobre la realidad en la que viven y sobre sus propios países de origen.

10 Cecilia, la protagonista femenina, proviene de una familia oaxaqueña en la que se reconoce apenas y de la que se emancipa al ganar una beca para estudiar un posgrado en París, tras una adolescencia pasada a refugiarse en los clásicos de la literatura francesa. Al llegar a Europa, en parte desilusionada con la imagen que se había hecho de la Ciudad Luz, afirma:

Llegué a vivir aquí en esos días y pasé los primeros meses en un ambiente de tarjeta postal. [...] Toda esa alegría primaveral me pareció no solo impostada sino decepcionante. Yo había dejado mi país para escapar del sonido omnipresente de los organilleros de Oaxaca. La algarabía mexicana me resultaba opresiva. La idea que tenía de París no era aquella en donde decenas de parejas de todas las edades se besaban en los parques y los andenes del metro, sino la de un lugar lluvioso donde la gente lee a Cioran y a La Rochefoucauld mientras sorbe, con labios fruncidos y preocupados, café expreso sin leche y sin azúcar. (Nettel, 2014: p. irr.) 
11 En este apartado, el deseo de Cecilia de desprenderse de sus orígenes y alejarse de los tópicos de la identidad mexicana se ve frustrado por el choque entre dos imaginarios opuestos: el de las fotografías de Cartier-Bresson - referencia apenas disimulada detrás de la imagen de los enamorados besándose en parques y andenes de metro- y el de figuras inconformistas como La Rochefoucauld y Cioran. Cecilia llega a París para reflejarse en el espejo europeo y construirse otra identidad vinculada al inconveniente de haber nacido y a la sensación de no pertenecer a ningún lugar. Casi paradójicamente, su decepción ante el «ambiente de tarjeta postal» que luce París a su llegada es prueba de ese sentimiento de «no estar del todo» que siempre acompaña al sujeto nómade. cubanos y ostenta su rechazo de las costumbres isleñas:

Vuelven a mí las calles malolientes y estropeadas de La Habana Vieja, el calor pegajoso al que nunca logré acostumbrarme, mis hermanos metiendo las manos sucias a la olla donde tarda en cocinarse la malanga, ese tubérculo sempiterno cuyo olor nauseabundo se esparce en toda casa, obligándome a salir al patio donde juegan los vecinos. [...] Facundo y yo teníamos casi la misma edad pero llevábamos una existencia que al menos por ese entonces me parecía muy distinta. Mientras que para mí las calles de El Cerro - en donde la casualidad quiso por un equívoco que yo naciera- constituían un territorio hostil, habitado por desconocidos con aspecto de delincuentes, para Facundo no eran otra cosa que una extensión del patio de recreo. (Nettel, 2014: p. irr.)

13 En esta cita, que une dos fragmentos situados a pocas líneas de distancia el uno del otro, se pueden apreciar los dos movimientos opuestos y complementarios que definen el carácter de Claudio: uno centrífugo, de huida, y uno centrípeto, de repliegue sobre sí mismo. Si el olor de la malanga le obliga a salir al patio, donde sus coetáneos transcurren alegremente su tiempo, este mismo espacio público, al igual que la calle, le inspira un rechazo aún mayor que lo empuja a refugiarse en la lectura, en el espacio acogedor de los libros, donde la identidad puede forjarse libremente, alimentándose de las múltiples voces e infinitas posibilidades vitales de sus protagonistas. A la Cuba natal, Claudio prefiere Adorno, Benjamin y Vallejo, autores de obras nomádicas, en las que la errancia es no solo una condición existencial sino también una cualidad del pensamiento.

14 Así, para los personajes de Después del invierno, el lugar de origen deja de ser una marca de la identidad para convertirse en una simple circunstancia, en un aspecto más accidental y secundario- de una identidad compleja que ambos protagonistas quieren construir por sí solos, desmontando tópicos y clichés. Sin embargo, a este rechazo del país natal no se opone una plena integración en los respectivos países de acogida, al contrario, Cecilia y Claudio experimentan un permanente sentimiento de soledad y extranjería:

Al salir de la escuela, podía pasar horas en una café mirando caminar a los peatones

[...] Me intrigaba el ritmo apremiante de esos pasos, tan distintos de los míos, que la mayoría de las veces, carecían de un destino preciso. [...] Era así de simple: ellos tenían claro lo que hacían en el mundo, yo no. Ellos eran protagonistas de algo apasionante o estúpido - como puede ser cualquier vida-, yo era la espectadora de una película cuyo inicio no recordaba. Tampoco es que sintiera la necesidad imperiosa de conocer aquello que tornaba interesante la vida de los otros. Mi aburrimiento no dejaba el menor resquicio a la curiosidad, ni siquiera al entusiasmo que surge ante la posibilidad de escapar al tedio. (Nettel, 2014: p. irr.) 
Ante el presente fugitivo, la muchedumbre y el bullicio de la calle, Cecilia se interroga sobre su propia errancia, que termina por asociar a una de las dos acepciones etimológicas del verbo errar, es decir, equivocarse. En este sentido, su deambular sin «un destino preciso» por la capital francesa no se parece en nada al vagabundeo de los escritores de finales del siglo XIX, sino que representa metafóricamente el desarraigo del sujeto nómade contemporáneo, incapaz de adaptarse a las aceleraciones, los desvíos y las líneas de fuga que dibujan el mapa del presente.

Claudio, en cambio, se protege de esas sensaciones atrincherándose en su piso de Manhattan, cuyas dos únicas ventanas - de unos treinta centímetros cuadrados- dan ambas a un muro:

Del otro lado, la ciudad despliega su rumor incesante. Imagino por un momento que esa pared no existe y que desde mi ventana puedo ver a la gente caminando a toda prisa, rumbo a sus trabajos o citas de negocios como gusanos retorciéndose en una pecera de vidrio. Entonces agradezco la casualidad que quiso poner una barrera entre mi cuerpo y el caos, para que al despertar me sienta limpio, aislado, protegido. (Nettel, 2014: p. irr.)

17 A diferencia de Cecilia, el exiliado cubano reacciona al sentimiento de extranjería que le inspira la megalópolis estadounidense con un individualismo crispado y exacerbado. Pero así como la mirada de Cecilia rompe el encanto literario de París, la mirada de Claudio sobre Nueva York - esa pecera de vidrio en la que las personas se retuercen como gusanos- deconstruye la imagen de prestigioso cosmopolitismo asociada a la ciudad. Así, ante los ojos de los protagonistas de la novela, las dos capitales del mestizaje múltiple se convierten en dos laberintos de errancia y desencanto.

Ante este doble rechazo, el del país de origen y el del país de acogida, la identidad deja de ser algo fijo para convertirse en un devenir perpetuo, en una modalidad del estaren-el-mundo que se da por arraigamientos sucesivos, simultáneos o cruzados. Al respecto, parece pertinente citar la definición de sujeto radicante que propone Nicolas Bourriaud:

Por su significado a la vez dinámico y dialógico, el adjetivo radicante califica a ese sujeto contemporáneo atormentado entre la necesidad de un vínculo con su entorno y las fuerzas del desarraigo, entre la globalización y la singularidad, entre la identidad y el aprendizaje del Otro. Define al sujeto como un objeto de negociaciones. (2009: 57)

Esta interpretación del sujeto contemporáneo también puede aplicarse a los personajes secundarios: a Ruth, amante judía de Claudio, a Haydée, cubana de origen marroquí, arraigada en París y en pareja con un chico indio, y a Tom, compañero italiano de Cecilia. Este último, al contar sus numerosos desplazamientos entre Italia, Estados Unidos y Francia, afirma contundentemente: «No me siento ni francés, ni totalmente italiano, mucho menos estadounidense. En realidad, soy un ser fronterizo. Ahí es donde me encuentro más cómodo, en las zonas intermedias» (Nettel, 2014: p. irr.). La identidad de los personajes de Después del invierno, y más generalmente del sujeto contemporáneo, es entonces el resultado de «una apropiación ecléctica de elementos variados, muchos de ellos foráneos o ajenos» (Aínsa, 2012: p. irr.). A medio camino entre varias culturas y atrapados en un ejercicio de traducción permanente, los personajes de Después del invierno encarnan el devenir fragmentario y precario de la identidad y, más precisamente, la «archipielización [...] de los discursos y de los relatos, entidades aisladas que se vinculan por líneas en filigrana» (Bourriaud, 2009: 119-120). 
Entre los sujetos nómades que habitan la novela, Haydée es, quizás, el personaje que mejor representa este concepto:

Debajo de esa cabellera rizada e impenetrable, albergaba una infinidad de preguntas sin respuestas a las que le encantaba dar vuelta en voz alta. De padre cubano y madre judía marroquí, de nacionalidad francesa pero apellido castizo, Haydée Cisneros se sentía implicada en la mayoría de las polémicas que suelen suscitarse en esta ciudad. Nunca he visto a alguien más dispuesto a ofenderse. No podía conversar sobre el embargo, el conflicto en las banlieues, la guerra en Israel sin sentirse involucrada. Cuando los demás defendían a Fidel Castro, ella sumía todo el exilio y la persecución de intelectuales y gays como algo personal. En cambio, si alguien lo criticaba, blandía los logros y los valores de la revolución en términos de enseñanza y salud que, comparados con el nivel general de América Latina, eran innegables. (Nettel, 2014: p. irr.)

Este apartado presenta la identidad de la joven mujer como un archipiélago de relatos, arraigamientos provisorios y convicciones contradictorias en permanente metamorfosis. En efecto, según el crítico francés, la identidad del sujeto radicante no es ni estable ni cerrada sobre sí misma, sino que «existe únicamente bajo la forma dinámica de su errancia y por los límites del circuito que delinea [...]: en otros términos, es el movimiento lo que permite, in fine, la constitución de la identidad» (2009: 61).

21 A la vista de estos elementos, parece legítimo afirmar que en Después del invierno, Guadalupe Nettel pone en escena el extrañamiento total del sujeto contemporáneo, para quien la identidad deja de ser un relato linear, que nos define retrospectivamente, para convertirse en una hibridación constante, en un viaje sin asideros fijos.

\section{Fragilidad de las relaciones humanas}

Si la «identidad del nómade es un inventario de huellas» (Braidotti, 2000: 45) por territorios en los que el individuo se arraiga de manera transitoria y precaria, los vínculos humanos que éste llega a establecer tienden a estar marcados por «la existencia simultánea del impulso hacia la libertad y el anhelo de pertenencia» (Bauman, 2006: 54). De ahí que los aspectos que mejor definen las relaciones humanas contemporáneas sean «la fragilidad [...], el sentimiento de inseguridad que esa fragilidad inspira y los deseos conflictivos que ese sentimiento despierta, provocando el impulso de estrechar los lazos, pero manteniéndolos al mismo tiempo flojos para poder desanudarlos» (2006: 8-9). En Después del invierno, Guadalupe Nettel capta las facetas y los matices de tal fragilidad, construyendo una red de conexiones y relaciones proteicas e inestables entre los personajes de la novela. En este sentido, poniendo en escena los anhelos, las frustraciones, los temores y los traumas del sujeto contemporáneo, la obra de la escritora mexicana traza una cartografía minuciosa y dinámica del imaginario social asociado a la errancia.

Uno de los rasgos principales de tal imaginario es la reducción de las relaciones humanas a simples conexiones (Bauman, 2006: 12), a vínculos deleznables que, a menudo, se estrechan solo por conveniencia y que pueden activarse o desactivarse de manera intermitente:

No negaré las virtudes de mi novia. Es atractiva y refinada. Pasear con ella es casi ostentoso, como pasear del brazo de un escaparate: bolso Lagerfeld, espejuelos Chanel. En pocas palabras, tiene dinero y estilo. Sobra decir que una mujer así, en la ciudad donde vivo, es una llave que abre todas las puertas, un Eleguá que despeja todos los caminos. (Nettel, 2014: p. irr.) 
apartado, Claudio hace un retrato elogioso de Ruth, una diseñadora que conoce en una fiesta en un loft de Brooklyn y con quien mantiene una relación interesada, repleta de mentiras y manipulaciones. Encarnación del amor sacrificial -Ruth significa «la compañera fiel»- esa mujer mayor se desvive por complacer a su amante y aliviar, así, su soledad. Halagado por su sumisión - resultado de una sabia combinación de ansiolíticos y antidepresivos-Claudio la explota para obtener un puesto de traductor en la ONU y satisfacer sus necesidades sexuales («bajo mis ingles furiosas, debe permanecer inmóvil, si es posible ni siquiera respirar», Nettel, 2014: p. irr.). Para sacar el máximo partido de sus encuentros, el exiliado cubano emplea su «técnica más efectiva: una mezcla intermitente de indiferencia e interés, de ternura y desprecio, que suele poner a las mujeres de rodillas» (Nettel, 2014: p. irr.). De esta manera, Claudio sintetiza la «alterabilidad» de las relaciones amorosas contemporáneas, esto es, «la transitoriedad y revocabilidad de todas ellas» (Bauman: 2006, 79), conforme las posibilidades que se les ofrecen a uno. El homo sexualis -sostiene Bauman- recorre el espacio global codo a codo con el homo consumens (2006: 71) y sus «relaciones de bolsillo» (2006: 38) demuestran la extensión a la realidad social del culto de lo instantáneo y lo descartable.

Aun cuando los sentimientos parecen más auténticos, las relaciones entre los personajes de Después del invierno parecen instalaciones provisorias, constantemente amenazadas por el devenir perpetuo de la vida:

Teníamos el pacto tácito de no hacernos preguntas. Solo sabíamos las cosas que el otro quería contar acerca de sí mismo. Yo había visto algunas fotos de su familia enmarcadas y dispuestas en sus libreros, pero nunca me habló de sus padres ni de nadie más. Tampoco le pregunté para qué se medicaba tanto, ni cuál era la razón de su cansancio constante. Decidí dejar que él abordara el asunto cuando le diera la gana. Nuestras conversaciones se limitaban casi siempre a lo que había a nuestro alrededor: la calle, los vecinos, los comerciantes del barrio, su trabajo en la librería cuyo nombre aparecía muchas veces en los precios de los libros que tenía en casa [...]. Tampoco llegué a saber si los compraba o si los adquiría de otra manera. (Nettel, 2014: p. irr.)

La incomunicación que caracteriza estas primeras citas entre Cecilia y Tom no deja de aumentar a lo largo de la novela, extendiéndose por ese «territorio inexplorado y sin mapas» (Bauman, 2006: 22) que es el encuentro con el Otro. En este sentido, su relación no es sino una modalidad íntima de la errancia, de ese vagar perpetuo e irrenunciable en búsqueda de una alteridad en la que reconocerse. La larga ausencia de Tom -apenas interrumpida por una tarjeta postal y un mensaje en el contestador- $y$, a su regreso, el empeoramiento progresivo de su misteriosa enfermedad hacen que, para Cecilia, ese acercamiento al Otro se convierta en un vertiginoso descenso hacia la pérdida de sí. En efecto, ante la muerte inevitable de su compañero y agotada por los interminables ires y venires entre el barrio de Ménilmontant y el hospital de las afueras donde está internado, Cecilia llega a decir: «Si era inevitable que Tom se marchara de este mundo, yo quería irme con él. Irnos juntos. Irnos juntos. Irnos juntos como quien emigra en pareja a otro continente.» (Nettel, 2014: p. irr.) En realidad, Tom la ha elegido solo para acompañarlo hasta el fin de sus días: «Tienes las cualidades que yo necesito» (Nettel, 2014: p. irr.), le había dicho después de un paseo por el cementerio de Père-Lachaise, donde la había llevado para mostrarle el nicho que acababa de comprarse.

En su trayectoria de sujetos errantes, Cecilia y Claudio terminan por encontrarse en París. Claudio, tras una crisis de nervios de Ruth, accede a acompañarla en un viaje de 
negocio, y Cecilia acepta la invitación de Haydée, cuando su amiga cubana le propone ir con ella a una cita con un viejo amigo, Claudio, ex-novio de su prima Susana. El encuentro entre ellos, como es de esperarse, es otro fracaso. Claudio se enamora, idealizándola, de Cecilia, pero cuando ella le visita en Nueva York, el hombre cede al chantaje emocional de Ruth y termina por dejar a Cecilia sola en su claustrofóbico piso de Manhattan. La chica, asustada por los rituales obsesivos de Claudio y cansada de esperarlo, vuelve a París sin pena ni remordimiento. Al contrario, el protagonista masculino, tras la partida de Cecilia, confiesa:

Pero por la mañana, [...] el primer pensamiento que me viene a la mente es Cecilia, la existencia de Cecilia, su dolorosa ausencia como la mordida de una serpiente. Entonces mirar a Ruth durmiendo a mi lado me resulta insoportable. [...] la sensación que me deja es la de un insondable vacío, la certeza de no encontrarme donde debiera, de estar errando mis actos. (Nettel, 2014: p. irr.)

Si Cecilia se interroga sobre el sentido de su errar al asentarse en París, Claudio llega a plantearse esta misma cuestión al perder a la chica mexicana. También en su caso, el verbo errar evoca tanto el sentimiento de no encontrarse en el lugar que le corresponde como una más profunda fractura de la identidad, la de la falta de dirección y sentido de la propia vida.

Atrapados en continuos procesos de desterritorialización y reterritorialización y divididos entre el ansia de pertenecer al Otro y el deseo de mantenerse fuera de su alcance, la errancia de Cecilia y Claudio también toma los senderos de la memoria.

Tras la muerte de Tom, Cecilia se abandona por completo al dolor de la pérdida y a un anestésico vagabundeo:

Imaginaba a esa gente volviendo a sus casas por la noche o a los albergues de beneficencia, cocinando cualquier cosa y comiendo de pie, directamente de la olla, mientras se compadecían de sí mismos como quien ha desarrollado un acto reflejo. [...] Puede ser cualquiera la gota que derrama uno de esos vasos precozmente saturados. Muchas de esas actitudes que me habían escandalizado tanto al llegar, me resultaban ahora justificadas. Yo misma formaba parte de las hordas de neuróticos y esquizofrénicos, que espantan a los turistas, pero me daba lo mismo. Aunque estaba sola, mis dominios se habían ampliado considerablemente. Ya no se limitaban a treinta metros cuadrados en un edificio vetusto y con olor a humedad. Mis dominios eran las calles de París, todas sus escaleras y sus refugios. Mis compañeros los marginales, los descarriados, los SDF y los demás parias. (Nettel, 2014: p. irr.)

En este apartado, la metáfora del vaso que se derrama expresa eficazmente el derrumbe emocional de la protagonista, que ahora entiende, o cree entender, el frenético errar de los parisinos. El dolor por la pérdida de su compañero la empuja a rebasar los límites de los lugares conocidos para, quizás, perderse también a sí misma, no solo psicológica sino también físicamente.

Por su parte, Claudio, superada la etapa de la rabia y la autoconmiseración, decide combatir el dolor de la pérdida saliendo a correr todas las mañanas. Pero si correr el maratón de la Ciudad de México le permite cerrar el ciclo de Cecilia, otra herida, más antigua y profunda, vuelve a asomarse a su memoria: la del suicidio de su ex-novia Susana tras el fin de su relación y la consiguiente búsqueda de su cadáver por doquier:

Finalmente, al cabo de aquel período interminable [...], movido por una suerte de intuición o presentimiento, pedí abrir el cuarto de servicio, donde nos acostábamos mientras su familia deambulaba por la casa. Fue ahí donde la encontré, ya medio putrefacta, colgando de una cuerda con la boca y los ojos abiertos. Eran esos ojos 
desorbitados y azules que me perseguían en el Upper West Side durante mis noches de insomnio, y me obligaban a salir corriendo al parque cada mañana para conseguir olvidarlos, al menos durante una parte del día. (Nettel, 2014: p. irr.) movedizos de París y Nueva York, Guadalupe Nettel asocia una escritura fragmentaria y vagabunda, que bien puede considerarse como una inevitable y muy acertada exigencia formal de la novela. Así, a una estructura novelesca linear y cerrada, la autora prefiere una composición dinámica y dialéctica, en la que los nudos argumentales -el sentimiento de «no estar del todo», el desencuentro permanente con el Otro y el presente huidizo y frenético- se inscriben en la trama según un modelo rizomático (Deleuze), esto es, siguiendo recorridos múltiples e inesperados. En efecto, al confiar la narración a sus dos protagonistas, cuyos soliloquios se suceden recíproca y repetidamente ${ }^{3}$, Guadalupe Nettel renuncia a dirigir los hilos de la trama hacia un final concluyente y a dar un sentido unívoco a las experiencias que viven los personajes. rasgo formal de Después del invierno. De esta manera, la escritora mexicana parece sugerir que, al ser la trayectoria vital de cada individuo un camino incierto por una realidad multipolar y cambiante, no existe una forma definitiva y terminante de tejer y leer una historia. En este sentido, la elección de dos voces tan distintas, una femenina y una masculina, y la complejidad de ambos personajes -antihéroes imperfectos y contradictorios de la altermodernidad-amplifican la sutileza dialéctica de la novela.

Una de las consecuencias de tal aproximación literaria a la realidad es la de construir un relato multifocalizado, en el que el choque entre perspectivas encontradas multiplica la polisemia intrínseca a toda realidad. A esto hay que añadir que, si en la primera parte de la obra, tal confrontación es implícita en la yuxtaposición sistemática de las vicisitudes que encaran los personajes, tras el encuentro entre los protagonistas, al avanzar incesante de la errancia de cada uno, se suma una doble lectura de las experiencias compartidas: 
En vez de decirme, como yo creí, la hora a la que su avión aterrizaba en Charles De Gaulle, Claudio me había dado la hora estimada en que aparecería en mi casa. De milagro me despertaron sus pasos subiendo las escaleras. [...] Ni siquiera tuve el tiempo de enjuagarme la cara. Abrí la puerta y, para compensar mi aspecto desaliñado, me esmeré en dibujar una enorme sonrisa de bienvenida. [...] Me dije que su hambre debía de ser infinita después de aquel viaje transatlántico y me sentí avergonzada de no tener más que pan, jugo y café en mi despensa. Él, sin embargo, no dijo nada y se limitó a comer sin dejar de mirarme. [...] Fue un momento de lo más incómodo y llegué incluso a desear que se fuera. (Nettel, 2014: p. irr.)

Marqué el código de entrada que había recibido por mensaje y subí cuatro pisos de escaleras para despertar a Cecilia. Al menos esa era mi intención. Ella estaba esperándome con la puerta abierta. [...] En la mesita de centro estaba dispuesto el desayuno. No tenía apetito. Había comido prácticamente lo mismo durante el vuelo pero me forcé a desayunar de nuevo para no desairarla. Mientras tanto imaginaba sus pechos, iguales a los que pintaba Diego Rivera, cuyos murales había visto en Chicago. (Nettel, 2014: p. irr.) los protagonistas ni las mismas impresiones ni los mismos pensamientos. En efecto, al entusiasmo y el deseo sexual de Claudio se opone el disgusto disfrazado de cortesía de Cecilia. Si, por un lado, tal desfase demuestra, una vez más, la complejidad y la fragilidad de los vínculos humanos, por otro lado, en el plan formal, es interesante destacar que los dos fragmentos aparecen en dos capítulos distintos, yuxtapuestos el uno al otro y mezclados a otros acontecimientos y reflexiones. Podría decirse, entonces, que la construcción multifocal de la novela está en parte a cargo de los lectores, a quienes corresponde la tarea de entretejer los hilos de la narración y aprehender así el movimiento dialéctico que existe entre las dos voces.

De manera parecida, en los lectores incumbe el deber de reconstruir el orden de algunos acontecimientos, cuya posición en la trama está sometida a las fluctuaciones del pensamiento de Claudio y Cecilia. Así, aunque la narración sigue un orden cronológico, este se ve interrumpido a menudo por digresiones retrospectivas, que establecen un movimiento continuo entre el presente y el pasado y entre un aquí y un allí siempre cambiantes:

Al principio Facundo se mantuvo tan imperturbable como antes, pero la edad no perdona a nadie y también él acabó sumándose a la paja del sábado en la tarde, aunque de manera mucho menos pudorosa: [...] en el silencio de la incipiente noche, eyaculaba salpicando con alarde las baldosas del patio o el muro a través del cual veíamos a Regla desnudarse.

A veces, mientras las notas del piano resuenan el pasillo de piedra, un muro de contención se impone entre esas imágenes y yo. Ese muro me ha permitido sobrevivir todos estos años, sabiendo que mi padre está enfermo y solo, en la provincia de Cienfuegos; que mis hermanos siguen viviendo en esa misma casa donde pasamos la infancia pero ahora con las familias que han formado. El disco termina y todo vuelve a la normalidad. Bendita sea la barrera que me mantiene seco, impermeable a las emociones. (Nettel, 2014: p. irr.)

En este apartado, el recuerdo del despertar sexual de Claudio en La Habana, detrás del muro del baño en el que se duchaba Regla, la prima de Facundo, es interrumpido por la imagen de otros muros, uno real, el del pasillo de piedra al que se reduce su espacio vital en Manhattan, y uno metafórico, el que el cubano suele levantar entre sí mismo y el género humano. Aquí, además, la condensación en pocas líneas de tiempos y lugares distintos se ve amplificada por el contraste entre el campo semántico de los líquidos, 
naturales y corporales, y el que Claudio asocia ingeniosamente a su rebuscada flema, a saber, la necesidad de mantenerse seco e impermeable a las emociones.

En ambos fragmentos, Guadalupe Nettel juega con los conceptos de sucesión y simultaneidad del espacio-tiempo, en el primer caso, multiplicando y poniendo a distancia el relato de un mismo acontecimiento y, en el segundo, condensando y superponiendo circunstancias distintas a través de la imagen, igualmente significativa, de un muro capaz de difuminar fronteras espaciales y temporales. De hecho, según Bourriaud, la dispersión espacio-temporal es otra característica de la estética radicante (2009: passim).

Un segundo aspecto crucial de Después del invierno, que sin embargo puede aplicarse a toda la obra de la escritora mexicana, es la atención hacia lo nimio y lo infraordinario. Lectora avisada de Georges Perec, cuyos libros favorecen los primeros acercamientos entre Cecilia y Tom, Guadalupe Nettel parece hacer suyos los interrogantes del autor franco-polaco:

Lo que realmente ocurre, lo que vivimos, lo demás, todo lo demás, ¿dónde está? Lo que ocurre cada día y vuelve cada día, lo trivial, lo cotidiano, lo evidente, lo común, lo ordinario, lo infraordinario, el ruido de fondo, lo habitual, ¿cómo dar cuenta de ello, cómo interrogarlo, cómo describirlo? [...] No lo interrogamos, no nos interroga, no plantea problemas, lo vivimos sin pensar en él, como si no vehiculase preguntas ni respuestas, como si no fuese portador de informaciones. [...] Cómo hablar de esas «cosas comunes», más bien cómo acorralarlas, cómo hacerlas salir, cómo darles un sentido, un idioma: que hablen por fin de lo que existe, de lo que somos. (Perec, 2010: 22-23)

El esmero con el que la autora, a través de sus personajes, se dedica a registrar los detalles de la vida cotidiana parece ser una manera de asumir el desafío planteado por Georges Perec: el de interrogar lo habitual para que vuelva a significar y para que contribuya a renovar la mirada que proyectamos sobre nosotros mismos y sobre la realidad. Así, en la introducción que escribe a la versión española de Lo infraordinario, Guadalupe Nettel celebra la reflexión del autor sobre el papel del espacio en la construcción de la identidad individual y de la memoria, considerándola como «una prueba de la lucidez extraordinaria que tenía Perec en materia de literatura» (Perec, 2010: 18). Es a la luz de estas apreciaciones que puede leerse, por ejemplo, el párrafo siguiente:

Podía pasar horas observando esos ruidos en los que nunca antes me había detenido. Empecé, por ejemplo, a escuchar las bocinas y las ruedas de los coches en el bulevar, pero también los movimientos y los carraspeos de la gente que vivía en el edificio, sus llamadas telefónicas. Comprendí que era posible descifrar la vida de todos ellos a través de los sonidos que emitían. [...] Quizás otra persona más sana habría aprovechado la ausencia de un ruido de fondo para leer, escuchar música o llamar a sus conocidos. Yo [...] preferí llevar el inventario de las actividades que tenían mis vecinos. (Nettel, 2014: p. irr.)

En este fragmento, la atención de la autora se concentra en uno de los detalles más inasibles de lo cotidiano: sus ruidos. Aunque Cecilia presenta tal actitud como la expresión de un temperamento abúlico -lo que no deja de ser verdad en la ficción de la novela-, el de llevar un inventario de los sonidos que nos envuelven y de descifrar la vida de quienes los producen a partir de ellos parece, sobre todo, un proyecto literario digno de Georges Perec. Al respecto, en Lo infraordinario, el mismo autor afirma:

Me importa poco que estas preguntas sean, aquí, fragmentarias, apenas indicativas de un método, como mucho de un proyecto. Me importa mucho que parezcan 
triviales e insignificantes: es precisamente lo que las hace tan esenciales o más que muchas otras a través de las cuales tratamos en vano de captar nuestra verdad.

(Perec, 2010: 24-25) que podría definirse como una poética de la errancia, es la noción de forma-trayecto. Así como lo sugiere Bourriaud en Radicante, en tanto principio de composición, el trayecto encarna la precariedad de la época contemporánea y constituye el principal recurso de la estética nómade. En este sentido, si la realidad es una "constelación de signos» (Bourriaud, 2009: 119) por la que nos paseamos, el arte y la literatura contemporáneas bien pueden considerarse como una errancia del sentido, como una tentativa de dibujar un itinerario o crear un recorrido en este paisaje. Solo una composición frágil, abierta y dinámica, entonces, puede reflejar tal camino del pensamiento. Los últimos capítulos de Después del invierno parecen encarnar esta idea, no solo porque los soliloquios de los dos protagonistas se cierran en torno a dos acontecimientos intrascendentes - el aroma a strudel de manzana, en el caso de Claudio, y las carreras desaforadas de unos críos en el parque, en el caso de Cecilia- sino también y, sobre todo, por las reflexiones que las preceden y que parecen demostrar su plena asunción de la errancia como condición vital del ser humano.

Tras perder una pierna en la explosión del maratón de Boston, a la que se habría escapado si hubiese socorrido a una atleta víctima de una crisis epiléptica, Claudio recuerda unas palabras de Ribeyro, un autor que le había hecho descubrir Cecilia:

«Seres imperfectos viviendo en un mundo imperfecto, estamos condenados a encontrar solo migajas de felicidad.» ¿Cuál es la alternativa? Quizás aceptar nuestro límites, nuestras contradicciones, nuestras muchas necesidades, tratar de ser más fuerte que el peso de toda culpa. [...] Vivir sin perder, en la medida de nuestras posibilidades, la capacidad para volver a un centro desde donde se puede confiar, esperar, ser-feliz-ahora-mismo-a-pesar-de-todo, a pesar del dolor y de la certeza de que la vida es, básicamente, imposibilidad y dolor. (Nettel, 2014: p. irr.)

La vida, parece sugerir Claudio, es una errancia perpetua, es andar, perderse, equivocarse y volver, una y otra vez, a buscar un centro, en el cual podamos saborear unos breves instantes de felicidad. Una felicidad que se esconde en los detalles de lo cotidiano, en el aroma a strudel de manzana que lo acoge «como si volviera de un largo viaje» (Nettel, 2014: p. irr.) en la puerta de casa de Ruth.

De manera parecida, Cecilia termina por asumir la condición errante de la vida humana buscando un equilibrio entre los luminosos detalles de la realidad cotidiana - unos niños jugando en el parque un día de primavera-y la literatura, refugio irrenunciable:

En una libreta roja de tapa dura comencé una especie de diario donde, con mucha frecuencia, anoto también mis recuerdos más importantes o las escenas de mi vida que, por una razón u otra, me obsesionan. Me gusta, por ejemplo, describir a personas con las que he vivido y he dejado de ver. Me apropio de ellas como personajes. A veces, las mezclo o les invento destinos verosímiles, bondadosos o macabros. No sé qué valor tenga todo eso ni como biografía ni como literatura, lo que sí puedo decir es que lo disfruto y con eso me es suficiente. (Nettel, 2014: p. irr.)

En este apartado, donde las fronteras entre la realidad de la autora y la ficción del personaje parecen difuminarse de nuevo, Cecilia esboza su personal poética de la 
errancia, hecha de apuntes fugitivos, obsesiones personales y escenas de la vida cotidiana. Si, como lo sugiere Braidotti, «la escritura es el proceso de anular la ilusoria estabilidad de identidades fijas, de hacer estallar la burbuja de la seguridad ontológica» (2000: 47), el gesto de crear personajes en el espacio de la página y de decidir su destino por medio de la escritura -el recurso más nomádico que existe- es quizás la única manera de aprehender y vivir con levedad la insoportable fragilidad de la existencia.

51 Así, con un lenguaje rico y llano y una sintaxis pulida y escurridiza, Guadalupe Nettel forja una verdadera poética de la errancia. Al convertir la escritura en un permanente descentramiento de todas las certidumbres, que dejan así de ser tales, la autora mexicana hace de los procesos de desterritorialización y reterritorialización de la sociedad contemporánea un instrumento de análisis eficaz y sofisticado.

\section{A modo de conclusión}

En el panorama de la literatura hispánica actual, la obra de Guadalupe Nettel se destaca como una de las representaciones más lúcidas y contundentes del nomadismo radical de la sociedad contemporánea. En efecto, en Después del invierno nos ofrece un retrato sagaz y covincente de nuestro presente y de sus múltiples facetas, logrando un equilibrio difícil entre lo universal y lo minúsculo. Con un estilo inconfundible en el que lo extraño, al igual que una lupa, indaga y revela lo cotidiano, la escritora mexicana traza los itinerarios vivenciales de dos protagonistas, en cuyas experiencias se mezclan los principales ingredientes de la altermodernidad, esto es: la afirmación progresiva de un imaginario colectivo transcultural y translingüístico ${ }^{4}$, la emergencia paralela de una ciudadanía flexible y transnacional y la transformación vertiginosa de los vínculos sociales y de las relaciones íntimas. Ello no obstante, en Después del invierno Guadalupe Nettel no ofrece ninguna respuesta definitiva, ningún metarrelato al que asirse para aprehender la realidad en la que vivimos. Al contrario, la autora elige el camino más largo, el de las preguntas y de los detalles, el de las dudas y de los sentimientos conflictivos para reconstruir en el espacio de la página los procesos erráticos que caracterizan la época actual. Así, detrás su final frágil y abierto se oculta, a nuestro parecer, la idea de que la literatura contemporánea solo puede escribirse desde los márgenes puesto que la identidad ya no es un relato sino una praxis, un itinerario de huellas que hay que apreciar por su devenir constante e imprevisible.

\section{BIBLIOGRAFÍA}

AínSA Fernando (2012), Palabras nómadas. Nueva cartografía de la pertenencia, Madrid, Frankfurt: Iberoamericana, Vervuert (ebook).

BAUMAN Zygmunt (2006), Amor líquido. Acerca de la fragilidad de los vínculos humanos, Buenos Aires: Fondo de Cultura Económica. 
BERND Zila \& DEI CAS-GIRALDI Norah [eds] (2014), Glossaires des mobilités culturelles, Bruxelles: Peter Lang.

BRAIDOTTI Rosi (2000), Sujetos nómades. Corporización y diferencia sexual en la teoría feminista contemporánea, Buenos Aires: Paidós.

BOURRIAUD Nicolas (2009), Radicante, Buenos Aires: Adriana Hidalgo Editora.

MONTOYA JUÁREZ Jesús \& ESTEBAN Ángel [eds] (2008), Entre lo local y lo global. La narrativa

latinoamericana en el cambio de siglo (1990-2006), Madrid, Frankfurt: Iberoamericana, Vervuert.

COPELLO Fernando, NEYROD Dominique \& VALVERDE Lucie [eds] (2018), Le nomadisme dans le monde

hispanique, 12.

NETTEL Guadalupe (2014), Después del invierno, Barcelona: Anagrama (ebook).

NOGUEROL Francisca (2008), «Narrar sin fronteras», J. MONTOYA JUÁREZ \& A. ESTEBAN [eds] (2008), Entre lo local y lo global. La narrativa latinoamericana en el cambio de siglo (1990-2006), Madrid, Frankfurt: Iberoamericana, Vervuert, 19-34.

PEREC Georges (1974) Espèces d'espaces, Paris: Éditions Galilée.

PEREC Georges (2010), Lo infraordinario, Madrid: Editorial Impedimenta (ebook).

\section{NOTAS}

1. La escritora mexicana transcurrió su niñez en Francia, país al que volvió para hacer un doctorado en la École de Hautes Études en Sciences Sociales de París. También ha vivido en Canadá y en España.

2. Guadalupe Nettel es autora de las novelas El huésped (2005), El cuerpo en que nací (2011) y Después del invierno (2014). También ha escrito dos libros de cuentos Pétalos y otras historias incómodas (2008) y El matrimonio de los peces rojos (2013). Como investigadora ha publicado: Para entender a Julio Cortázar (2008) y Octavio Paz. Las palabras en libertad (2014).

3. La alternancia entre las dos voces se interrumpe al final de la novela, con dos capítulos narrados por la protagonista femenina.

4. De manera puntual aparecen en el libro palabras en inglés y francés, síntomas de la identidad transfronteriza de los personajes.

\section{RESÚMENES}

Si existe una tradición en la literatura latinoamericana definida por la desterritorialización de sus autores y por el rechazo de cualquier tipo de esencialismo nacional, lo que mejor define la narrativa actual es su marcada condición nomádica (Noguerol, 2008; Aínsa, 2012). La inmersión de esta narrativa sin fronteras en el amplio espectro de la literatura occidental dibuja una «geografía alternativa de la pertenencia» (Aínsa, 2012), caracterizada por una fuerte hibridación cultural y por una paralela reflexión sobre el acto creativo y la subjetividad contemporánea. En esta línea se inscribe la obra de la mexicana Guadalupe Nettel (1973), cuya novela Después del 
invierno (2014) interroga los paradigmas estéticos, sociales y culturales que rigen la sociedad-red contemporánea. A partir de una doble focalización interna -masculina y femenina- y de la puesta en escena de una variedad de tránsitos, reales y simbólicos, Nettel explora algunas fundamentales experiencias de la época actual: la migración, el viaje, la enfermedad física y psíquica, el amor y sus desencuentros, la pérdida. El artículo propone un análisis de la obra a partir de las nociones de errancia e identidad nómade (Braidotti, 2000; Bourriaud, 2009) para destacar sus logros más significativos: la representación de una subjetividad descentrada y radicante, la puesta en escena de la fragilidad de las relaciones humanas (Bauman, 2006) y la elaboración de una poética de la errancia. Tres aspectos que hacen de Después del invierno una de las obras más emblemática de la altermodernidad.

S'il existe une tradition dans la littérature latino-américaine liée à la déterritorialisation de ses écrivains et au refus de toute forme d'essentialisme identitaire, ce qui définit le mieux la littérature actuelle est sa condition nomade (Noguerol, 2008; Aínsa, 2012). L'inclusion de cette narrative sans frontières dans le panorama de la littérature occidentale dessine ce que Aínsa a décrit comme une "géographie alternative de l'appartenance» (2012), dont les aspects les plus significatifs sont les suivants : l'hybridation culturelle et la réflexion des auteurs sur le processus créatif et sur la subjectivité contemporaine. L'œuvre de la Mexicaine Guadalupe Nettel (1973), et son roman Después del invierno tout particulièrement, s'inscrit dans cette perspective, en interrogeant les paradigmes esthétiques, sociaux et culturels qui régissent la société réseau contemporaine. À partir d'une double focalisation interne - masculine et féminine - et de la mise en scène d'une variété de passages, réels et symboliques, Nettel explore quelques expériences fondamentales de l'époque actuelle : la migration, le voyage, la maladie physique et psychique, l'amour et ses revers, la perte. L'article propose une analyse de l'œuvre à partir des notions d'errance et d'identité nomade (Braidotti, 2000; Bourriaud, 2009) afin de mettre en valeur ses aspects les plus réussis : la représentation d'une subjectivité décentrée et radicante, la mise en scène de la fragilité des relations humaines (Bauman, 2006) et l'élaboration d'une poétique de l'errance. Trois marques distinctives qui font de Después del invierno un des romans les plus emblématiques de l'altermodernité.

If Latin-American writers have always strived not to be reduced to their national identity, their contemporary novels seem to echo the nomadic condition of ours times (Noguerol, 2008; Aínsa, 2012). The inclusion of such a transnational literature in the landscape of Western canon sketch a different map of belonging (Aínsa, 2012). Its main aspects are: the cultural hybridisation and the dissection of contemporary subjectivity and literary creation itself. The work of the Mexican Guadalupe Nettel (1973) falls in this category. Her novel Después del invierno (2014) questions the aesthetic, social and cultural paradigms that lead our society. Through a double internal focalization-that of a Cuban middle-aged man in New York and that of a Mexican young woman in Paris-Nettel scrutinise some fundamental experiences of our nomadic times: migration, illness, love and loss. This article uses the notions of nomadic subject (Braidotti, 2000) and radicant aesthetics (Bourriaud, 2009) to examine how Guadalupe Nettel catches the essence of Altermodernity (Bourriaud, 2009). Overall, the study found that her novel focuses on three main aspects: it represents a decentred and radicant subject, it dramatizes the fragility of human relationships (Bauman, 2006) and it creates a "nomadic poetics". These findings suggest that Después del invierno is one of the most emblematic novels of Altermodernity. 
ÍNDICE

Mots-clés: errance, sujet nomade, esthétique radicante, déterritorialisation

Keywords: nomadic subject, radicant aesthetics, deterritorialisation

Palabras claves: errancia, sujeto nómade, estética radicante, desterritorialización

\section{AUTOR}

\section{ROBERTA TENNENINI}

Université de Toulouse Jean Jaurès 